1 Aherne, G, Transactions of the Ophthalmological Societies of the UK, 1974, 94, 938.

${ }^{2}$ Kitchin, F D, and Ellsworth, R M, fournal of Medical Genetics, 1974, 11, 244.

${ }^{3}$ Chan, H, and Pratt, C B, Fournal of the National Cancer Institute, 1977, $58,205$.

4 Gordon, H, Birth Defects Original Article Series, 1974, 10, No 10.

5 Doll, R, Muir, C, and Waterhouse, J, Cancer Incidence in Five Continents, vol 2. Berlin, Springer-Verlag, 1970.

(Accepted 27 September 1977)

Unit of Clinical Epidemiology, University of Oxford, Oxford OX3 7LF

JEAN FEDRICK, MA, research epidemiologist

J A BALDWIN, FFCM, FRCPSYCH, medical director

\section{Comparison of intravenous and nebulised salbutamol in initial treatment of severe asthma}

Salbutamol has been assessed in the initial treatment of acute severe asthma ${ }^{12}$ but the optimum route and duration of administration have not been established. We have compared the effects of salbutamol given by intravenous infusion with those of wet, nebulised salbutamol in a randomised, double-blind trial on patients admitted to the emergency department with acute severe asthma.

\section{Patients, methods, and results}

Sixteen patients were included in the study, which was approved by the hospital's ethical committee. Informed consent was obtained. Criteria for admission were: age 15-65 years; asthma unresponsive to normal daily medication; no administration of hydrocortisone in previous six hours or recent change in dosage of other oral corticosteroids; and a peak flow (Wright meter) 1201 or less/min. Medication before admission was noted.

All patients received $40 \%$ oxygen through a Mix-o-mask (Blease Medical Equipment Ltd) for five minutes before arterial puncture, and all were given hydrocortisone $250 \mathrm{mg}$ intravenously. Pulse rate, peak flow, and forced expiratory volume in one second $\left(\mathrm{FEV}_{1}\right)$ were measured. The contents of a numbered ampoule containing either $900 \mu \mathrm{g}$ salbutamol or placebo were injected into an infusion bag containing $500 \mathrm{ml}$ physiological saline. The contents of a similarly numbered bottle containing either placebo or $10 \mathrm{mg}$ salbutamol in $10 \mathrm{ml}$ saline were placed in a plastic nebuliser (Sandoz Products Ltd), which was attached to the mask. Patients received either placebo by nebuliser and salbutamol by intravenous infusion or vice versa. The infusion and nebulisation were adjusted to run for 45 minutes. At the end of treatment the observations were repeated while the patients breathed $40 \%$ oxygen.

There was no difference in the severity of asthma between the two groups before treatment as judged by peak flow, $\mathrm{FEV}_{1}$, blood gas tensions, and pulse rate (see table). Treatment before admission was similar in the two groups. Both groups showed significant improvement in $F_{1}$ after treatment $(\mathrm{P}<0.02$, paired $t$ test $)$. There was no difference between the effects of nebulised and intravenously administered salbutamol as measured by changes in $\mathrm{FEV}_{1}$, peak flow, and blood gas tensions in respect of either the mean results or the proportion of patients showing a favourable response. Mean pulse rate fell in the nebuliser group and rose in the intravenously-treated group; this difference was significant $(P<0.02)$.

All but one of the patients given nebulised salbutamol said that their breathing had become much easier, whereas out of seven given intravenous salbutamol, two felt no better or felt tighter in the chest, and two had dizziness or shaking at the end of treatment. The trial was abandoned in two patients, in one case because of uncontrollable shaking, and in the other because of extreme agitation. Both had received intravenous salbutamol.

\section{Comment}

Hetzel and Clark ${ }^{3}$ reported a more prolonged bronchodilator effect with aerosol salbutamol than with the intravenous drug in controlled asthmatics, and suggested a trial in acute asthma. In selecting the rate of infusion of salbutamol we were anxious to obtain maximum bronchodilator effect, and $20 \mu \mathrm{g} / \mathrm{min}$ had been suggested as appropriate. ${ }^{4}$ This rate, however, caused an appreciable rise in pulse rate, numerous ectopic beats in one patient, and undesirable side effects in five out of nine patients. A lower rate is probably advisable. Nebulised salbutamol had a similar bronchodilator effect, however, and was free of side effects.

Nebuliser treatment with unassisted breathing is just as effective as when given with intermittent positive-pressure ventilation, even in the presence of airways obstruction. ${ }^{5}$ With the availability of cheap, effective nebulisers and masks, this method of administration is recommended in severe asthma.

Requests for reprints should be sent to Dr J S Milledge.

${ }^{1}$ Fitchett, D H, McNicol, M W, and Riordan, J F, British Medical fournal, 1975, 1, 53.

2 Spiro, S G, et al, Thorax, 1975, 30, 236.

${ }^{3}$ Hetzel, M R, and Clark, T J H, British Medical fournal, 1976, 2, 919.

4 Smith, A P, British fournal of Clinical Pharmacology, 1974, 1, 399.

5 Dolovich, M B, et al, American Review of Respiratory Diseases, 1977, 115, 397.

(Accepted 20 September 1977)

\section{Northwick Park Hospital and Clinical Research Centre, Harrow,} Middlesex HA1 3UJ

$P$ LAWFORD, MRCP, registrar

B J M JONES, MB, MRCP, senior house officer (now medical registrar, Royal Devon and Exeter Hospital (Wonford), Exeter EX2 5DW)

J S MILLEDGE, MD, FRCP, consultant physician

Results before and changes in results after receiving salbutamol 10 mg by nebuliser or $900 \mu g$ by intravenous infusion over 45 minutes. Blood gas pressures measured while breathing $40 \%$ oxygen

\begin{tabular}{|c|c|c|c|c|c|c|c|c|c|c|}
\hline \multirow{2}{*}{ Trial No } & \multicolumn{2}{|c|}{$\mathrm{FEV}_{1}(\mathbf{l})$} & \multicolumn{2}{|c|}{ Peak flow rate $(1 / \mathrm{min})$} & \multicolumn{2}{|c|}{ Pulse rate (beats/min) } & \multicolumn{2}{|c|}{$\mathrm{PaO}_{2}(\mathrm{kPa})$} & \multicolumn{2}{|c|}{$\mathrm{PaCO}_{3}(\mathrm{kPa})$} \\
\hline & Initial value & Change & Initial value & Change & Initial value & Change & Initial value & Change & Initial value & Change \\
\hline \multicolumn{11}{|c|}{ Nebulised salbutamol } \\
\hline $\begin{array}{r}2 \\
7 \\
9 \\
10 \\
12 \\
13 \\
14 \\
\end{array}$ & $\begin{array}{l}0.52 \\
0.35 \\
0.64 \\
0.35 \\
0.73 \\
0.53 \\
\end{array}$ & $\begin{array}{c}0 \\
+0.15 \\
+0.39 \\
+0.25 \\
+0.21 \\
+0.23 \\
\end{array}$ & $\begin{array}{r}86 \\
90 \\
60 \\
110 \\
70 \\
110 \\
51\end{array}$ & $\begin{array}{l}-4 \\
+130 \\
+5 \\
+130 \\
+35 \\
+38 \\
+24 \\
\end{array}$ & $\begin{array}{r}130 \\
80 \\
98 \\
128 \\
128 \\
80 \\
160 \\
\end{array}$ & $\begin{array}{l}+22 \\
+4 \\
-14 \\
-30 \\
-12 \\
0 \\
-40 \\
\end{array}$ & $\begin{array}{r}10.4 \\
10.5 \\
11.9 \\
15.0 \\
12.5 \\
7.9 \\
\end{array}$ & $\begin{array}{l}-0.6 \\
+2.7 \\
-0.6 \\
+4.7 \\
-4.7 \\
-2.6 \\
\end{array}$ & $\begin{array}{l}4 \cdot 6 \\
5 \cdot 3 \\
4 \cdot 5 \\
5 \cdot 0 \\
5 \cdot 4 \\
8 \cdot 8 \\
\end{array}$ & $\begin{array}{l}-0.4 \\
-0.2 \\
-0.7 \\
-0.2 \\
-0.8 \\
-2.2\end{array}$ \\
\hline Mean \pm SD & $0.52 \pm 0.15$ & $+0.21 \pm 0.13$ & $82 \pm 23$ & $+51 \pm 56$ & $115 \pm 30$ & $-10 \pm 21$ & $11.4 \pm 2.4$ & $-0.2 \pm 1.6$ & $5.6 \pm 1.6$ & $-0.8 \pm 0.8$ \\
\hline \multicolumn{11}{|c|}{ Intravenous salbutamol } \\
\hline $\begin{array}{r}3 \\
4 \\
11 \\
15 \\
16 \\
20 \\
21\end{array}$ & $\begin{array}{l}0.46 \\
0.43 \\
0.39 \\
0.98 \\
0.75 \\
0.84 \\
0.68\end{array}$ & $\begin{array}{l}-0.09 \\
+0.52 \\
+0.17 \\
+0.50 \\
+1.05 \\
+0.54 \\
+0.40\end{array}$ & $\begin{array}{r}60 \\
53 \\
85 \\
110 \\
120 \\
85\end{array}$ & $\begin{array}{l}-17 \\
-5 \\
-5 \\
+164 \\
+30 \\
+60\end{array}$ & $\begin{array}{r}120 \\
132 \\
148 \\
132 \\
88 \\
120 \\
96\end{array}$ & \begin{tabular}{c|}
+4 \\
+20 \\
+16 \\
+8 \\
+32 \\
Ectopic beats \\
+32
\end{tabular} & $\begin{array}{r}9 \cdot 3 \\
11 \cdot 7 \\
11 \cdot 6 \\
12 \cdot 3 \\
11 \cdot 4 \\
17 \cdot 4\end{array}$ & $\begin{array}{l}-0.9 \\
+2.3 \\
+0.6 \\
+0.5 \\
+0.2 \\
-3.4\end{array}$ & $\begin{array}{l}4 \cdot 5 \\
5 \cdot 6 \\
4 \cdot 4 \\
4 \cdot 3 \\
4 \cdot 4 \\
4 \cdot 8\end{array}$ & $\begin{array}{l}+2.8 \\
-0.2 \\
+0.4 \\
-0.4 \\
-0.4 \\
-0.7\end{array}$ \\
\hline Mean \pm SD & $0.68 \pm 0.24$ & $+0.44 \pm 0.35$ & $86 \pm 26$ & $+38 \pm 68$ & $119 \pm 21$ & $+19 \pm 12$ & $12 \cdot 3 \pm 2 \cdot 7$ & $+0.3 \pm 1.3$ & $4 \cdot 7 \pm 0.5$ & $+0.3 \pm 1 \cdot 3$ \\
\hline
\end{tabular}

$\mathrm{FEV}_{1}=$ Forced expiratory volume in one second

EV 1 Forced expiratory volume in one second. 